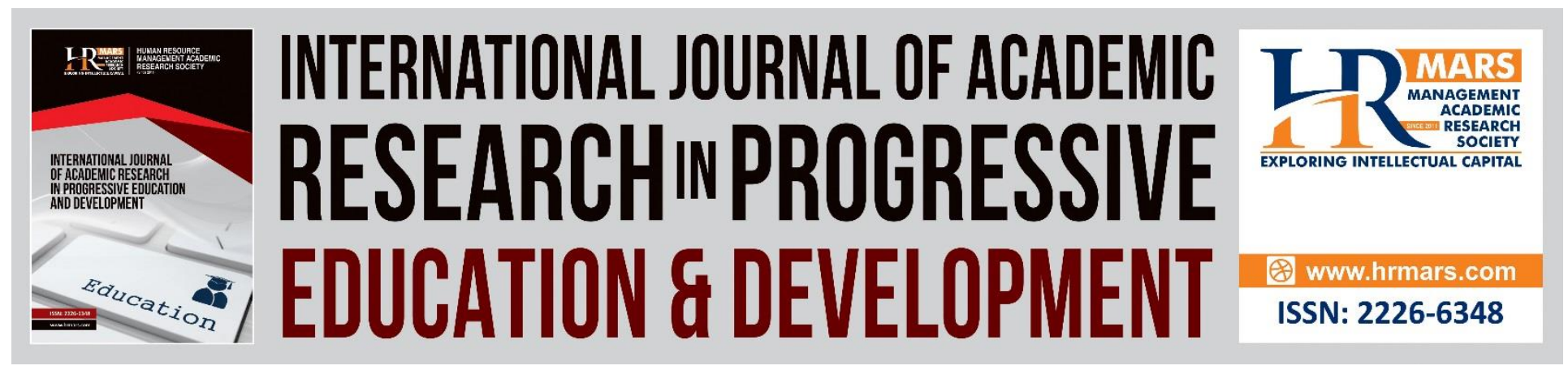

\title{
E-Learn: An Online Platform for Teaching and Learning
}

\author{
Malissa Maria Mahmud, Mohd Syuhaidi Abu Bakar
}

To Link this Article: http://dx.doi.org/10.6007/IJARPED/v9-i4/8265

DOI:10.6007/IJARPED/v9-i4/8265

Received: 10 November 2020, Revised: 01 December 2020, Accepted: 18 December 2020

Published Online: 10 January 2021

In-Text Citation: (Mahmud \& Bakar, 2021)

To Cite this Article: Mahmud, M. M., \& Bakar, M. S. A. (2021). E-Learn: An Online Platform for Teaching and Learning. International Journal of Academic Research in Progressive Education and Development, 9(4), 7891.

Copyright: (C) 2021 The Author(s)

Published by Human Resource Management Academic Research Society (www.hrmars.com)

This article is published under the Creative Commons Attribution (CC BY 4.0) license. Anyone may reproduce, distribute, translate and create derivative works of this article (for both commercial and non-commercial purposes), subject to full attribution to the original publication and authors. The full terms of this license may be seen at: http://creativecommons.org/licences/by/4.0/legalcode

Vol. 9(4) 2021, Pg. 78 - 91

http://hrmars.com/index.php/pages/detail/IJARPED

JOURNAL HOMEPAGE

Full Terms \& Conditions of access and use can be found at http://hrmars.com/index.php/pages/detail/publication-ethics 


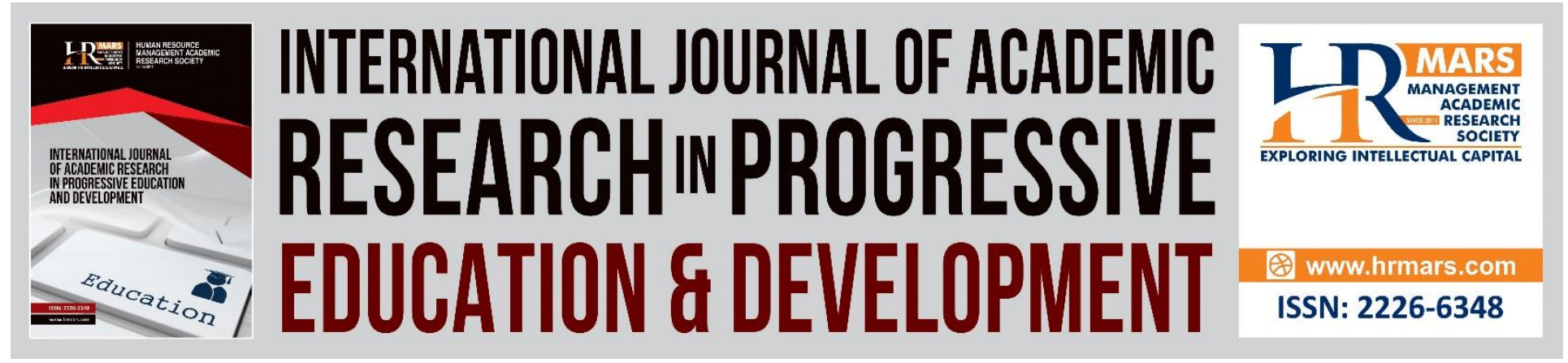

\title{
E-Learn: An Online Platform for Teaching and Learning
}

\author{
Malissa Maria Mahmud \\ Centre for English Language Studies, Sunway University, No. 5, Jalan, Universiti, Bandar Sunway, \\ 47500, Petaling Jaya, Selangor, Malaysia \\ Email: malissam@sunway.edu.my
}

Mohd Syuhaidi Abu Bakar

Faculty of Film, Theatre and Animation, Universiti Teknologi MARA, Puncak Perdana, 40450

Shah Alam, Selangor, Malaysia

Email: syuhaidi@uitm.edu.my

\begin{abstract}
On the $18^{\text {th }}$ of March, 2020, a Movement Control Order (MCO) was announced by the Malaysian government, and with the announcement, numerous regulations have been imposed to the public under the Prevention and Control of Infectious Diseases Act 1988, to prevent and curb the spread of COVID-19. The whole world was shocked and the experts were rattled. COVID-19 has brought the world to a standstill. The pandemic has affected all walks of life and sectors, including the education sector. Nationwide lockdown has prompted drastic changes, pushing the stakeholders to completely overhaul existing educational practices and strategies, with limited time and resources. Although the past decades have seen radical change in underlying beliefs and theories in the context of teaching and learning, the unforeseen, inadvertent and pushed transition from the orthodoxy of face to face, classroom-centric to $100 \%$ online has become a gamechanger, instigating significant and widespread presence of technological-enhanced or digital-supported instructions. Amid the upheaval, and despite institutional and individual constraints, academics and universities were resilient, migrating and converting lessons online, leveraging on numerous digital/ online learning platforms (OLPs), at a breakneck pace. However, the questions lie in how quickly can the students adapt, and how effective are these OLPs in scaffolding the 'new norm' of interactions? In fact, some researchers have argued that there are disparities between potentials and solutions fashioned by technology in education. In view of these major adjustments to the teaching and learning environments, this study is aimed to examine the effectiveness of elearn, a web-based online learning platform, specifically its perceived usefulness, perceived satisfaction and perceived facilitation of student-teacher and
\end{abstract}


student-student interactions on elearn. Findings, implications and future researches are discussed in following sections.

Keywords: Online Teaching and Learning, Usefulness, Satisfaction, Interaction, Covid-19, eLearn

\section{Introduction}

Despite the Covid-19 pandemic, educational institutions in Malaysia have embarked on an unprecedented journey to find a balance between the delineated MCO regulations, and the continuation of studies for their respective students. Many have resorted to quick remedies using off-the-rack technological solutions, in an attempt to mitigate the circumstance (Teras et al., 2020). A number of these solutions have been argued as a new market strategy, created by the commercial digital learning platforms providers, which have been censured and deemed as poorly designed in the aspect of pedagogical principles (Hodges et al., 2020; Janus, 2020; Mertala, 2019; Selwyn 2010). Nonetheless, numerous studies reported positive repercussions on the pedagogically more innovative and engaging, technological augmented deliveries, which have brought upon positive motivation, immediacy and interaction within the landscape of teaching and learning (Crawford, 2017; Halili, 2019; Mahmud, 2018). Deliberating on similar findings, it was reported that students felt more motivated and had better attitudes towards learning (Sundgren, 2017; Mahmud et al., 2019; Bernacki et al., 2020; Stephens \& Coryell, 2020), thus contributing to one of the important attributes to the success of computer-assisted environments. With the succinct background illustrated and disparity of knowledge established, this study employs a self-designed survey, developed based on theoretical foundations of the identified variables to answer the following questions:

1. What are the useful features of eLearn that facilitate learning?

2. What are the features on elearn related to students' perceived levels of satisfaction?

3. What are the features on elearn that facilitate interactions between students and students, and students and lecturers?

\section{Perceived Usefulness}

Embedded with well-designed features that scaffold remote teaching and learning, eLearn has varying degrees of practicality to its users. One of the essential criteria in the adoption of technology is perceived usefulness, which correlates with students' behavioral intention to supplement, complement, or complete their studies via an OLP. Perceived usefulness is also deemed as an indicator to demonstrate the extent of students' acceptance towards the integrated technology, which leads to students' satisfaction (Alqahtani \& Mohammad, 2015). In fact, one of the constructs in the Technology Acceptance Model (TAM) (Davis, Bagozzi \& Warshaw, 1989), (see Figure 1), is perceived usefulness, which defines the degree to which a person believes that using a particular system would enhance his or her job performance. This factor significantly influences learners' intention to employ technology. 
INTERNATIONAL JOURNAL OF ACADEMIC RESEARCH IN PROGRESSIVE EDUCATION AND DEVELOPMENT

Vol. 9, No. 4, 2021, E-ISSN: $2226-6348$ @ 2021 HRMARS

Figure 1: Technology Acceptance Model (TAM) (Davis, Bagozzi \& Warshaw, 1989, p.985).

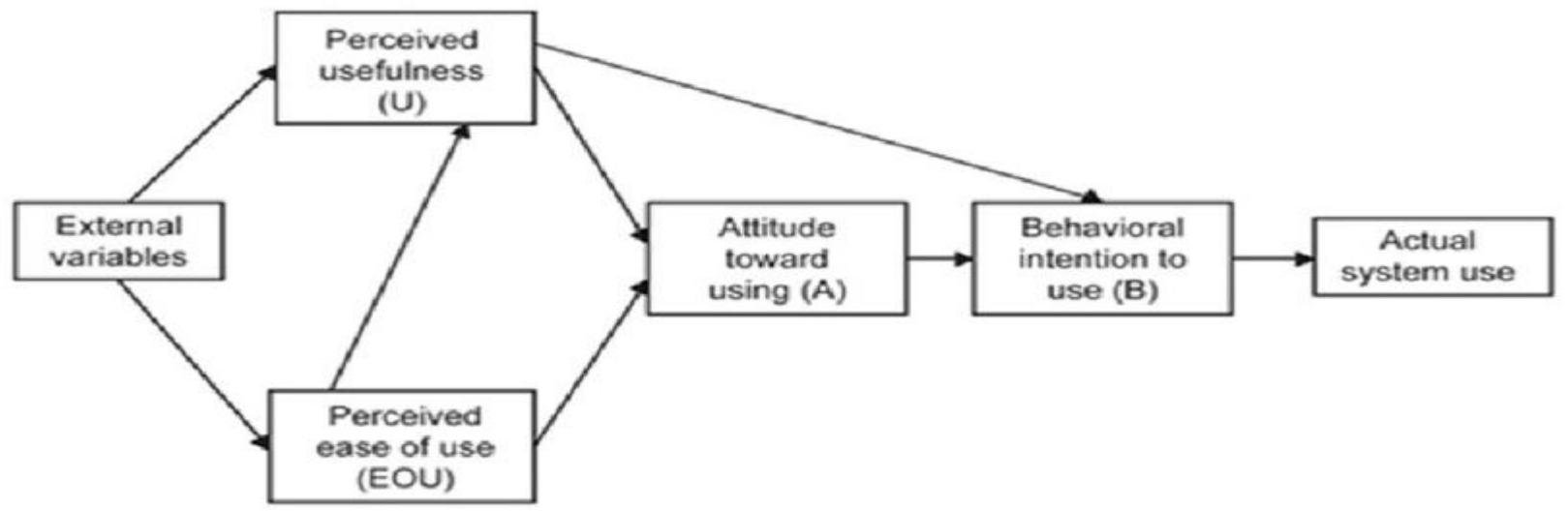

Firstly, the distinct characteristics of OLPs can potentially lead to positive impacts towards students' learning and academic performance, creating interdependent relationship between students and knowledge acquisition. For example, some OLPs are deemed as useful when it creates an enjoyable online learning environment (Sahin, 2019), encourages students to actively participate, which in turns resulted in greater motivation to study (Kerzic et al., 2019), and simultaneously increases the interaction and engagement between learners $(\mathrm{Wu}, \mathrm{Wu}, \& \mathrm{Li}$, 2019). Next, the interaction of other users such as lecturers or peers with the platform or content within the platform also motivates students to perceive it as useful. As such, learners find the use of e-learn platform particularly valuable if it is accompanied with individual help, teacher's feedback, positive teacher-student interaction (Annansingh, 2019; Aris \& Orcos, 2019), elements of gamification (Hallifax et al., 2019; Palomino et al., 2019), and class-wide discussion that advances their conceptual understanding and knowledge construction (Wu, Wu, \& Li, 2019). The eLearn platform facilitates the said functions, forming evident benefits for both learner and instructor. Lastly, the efficiency of the OLP when it is used to conduct tests and other forms of student performance evaluation is also crucial in influencing the perceived usefulness of the platform. For example, students have reported higher levels of enjoyment and competition when using online platforms to replicate a standardized testing environment (Sahin, 2019). This is because OLPs provide feedback to both teachers and learners (Permatasari et al., 2019). Feedback is crucial in understanding the topic or lesson learned during the online learning sessions; therefore, the efficiency of assessments and tests carried out on eLearn tends to influence the perceived usefulness of these OLPs. Perceived usefulness towards an OLP such as eLearn can be influenced by the characteristics of the OLP itself, the interaction of the users with the platform, and the efficiency of the platform when used to conduct tests. Likewise, as the perceived usefulness of the platform increases, the students would be more likely to utilize it to support their learning. This is in line with a past study by Faqih (2016) and Zhai \& Shi (2020), where results demonstrated that perceived usefulness has a positive influence in increasing the behavioral intention to adopt e-learning systems, an essential indicator to gauge the extent of students' acceptance towards technological integration. 
Vol. 9, No. 4, 2021, E-ISSN: $2226-6348$ @ 2021 HRMARS

\section{eLearn and Students Satisfaction}

Student satisfaction reflects how learners view their learning experience. According to Horzum, "satisfaction can be defined as the fulfillment and pleasure level of the students about various aspects of the learning service received in an online learning program" (2017, p. 506). Past researches have ascertained that satisfaction with online classes are correlated with these variables; course, faculty, and student (Blackmon \& Major, 2012; Cochran et al, 2016). In a similar vein, satisfaction is underscored as one of the most important aspects that contributes and shapes the quality of online instruction (Allen \& Seaman, 2010).

Mobile devices are part of daily modern life, and students employ the accessible mobile applications to support their learning process. The use of mobile technology in education provides the opportunity to reimagine teaching and learning (Heflin et al., 2017). New technologies increase flexibility, revamping archaic, one size fits all pedagogies. Taking this into account, online courses may see a huge benefit in student learning when OLPs are designed for use with mobile devices on top of the web-based applications, and in this case, eLearn proffers both web-based and mobile applications for the convenience of its users. However, the ubiquitous usage alone might not represent a robust evidence to justify its impact on students' performance (Bulman \& Fairlie, 2016). Thus, the design of OLPs necessitates architectural and application features to ensure extensibility and adaptability. In addition to the adaptive design, assessment tools are an important determinant of the effectiveness and quality of an online course, therefore becomes a vital factor that affects the satisfaction (Mahmud et al., 2020). As an OLP, eLearn allows lecturers to conduct quizzes and tests for students to complete the required assessments.

More importantly, these online assessment tools are highly interactive, customizable, trustworthy, secure, and can be accessed via multiple devices. Rodriguez et al. (2018) showed that using different assessment methods facilitates the relationship between students and teachers. In this context, the various methods of assessing a student can improve their performance as this is normally associated with receiving multiple feedback from the teacher or instructor. Besides, eLearn incorporates communication tools, including a bulletin board and chat room (Kattoua et al., 2016). These communication tools allow learners to interact with their peers and lecturers whenever they want. In addition, Gray \& Diloreto (2016) stated that active discussion among course participants significantly affected students' satisfaction and perceived learning. It is non-trivial that teacher-student interaction creates positive relationships in the classroom and leads to effective learning and satisfaction (Ahmad et al., 2017). As a result, interactive tools contribute to student satisfaction when using eLearn. Students feel satisfied when using OLPs that can integrate into mobile devices and also when OLPs are able to integrate features to enable quizzes, tests, and other assessments, and comes with adequate interactive tools to make the learning experience better.

\section{Facilitated Interactions and eLearn Features}

The crux of understanding in a learning process is asking questions and engaging in regular interactions. To better understand the mechanisms of interpersonal interaction and 
transactional distance, Moore (1989) identified three types of interaction; student-content interaction, student-student interaction, and student-faculty interaction. At this juncture, interaction between learners and other learners or with the instructor appears as a defining characteristic in quality learning experiences. Mahmud and Ismail stated that the tenet of quality, which constitutes both results and feedback obtained from students and teachers specifically, and the stakeholders generally, are essential to the restructuring and redesigning existing techsupported pedagogies (2020). The importance of student-teacher interaction is so prevalent that it is believed to be a basic need for learning to ensue, but some may argue that students suffer from the insufficient interactions in technology-supported instructions. Even when they are not able to understand the lessons, students are afraid to ask questions due to disapproval, or deemed to be a defiant to a perceivable social characteristic, which reinforces lack of online communication self-efficacy (Chung et al., 2020). This consequently impacts the students' overall readiness and performance.

In the epicenter of the educational landscape, interactions between learners and instructors are one of the key factors affecting the development of learners. The interactions between instructors and students affect the learning atmosphere. When teachers create a comfortable and conducive learning environment, students would be able to engage, have better motivation and a good learning experience (Ozhan \& Kocadere, 2020). Similarly, students tend to feel more motivated and positive when learning environment induces positivity, especially when there are collaborative interactions among the students and teacher. Instructors for instance play a significant role in shaping the academic achievements of students (Akhtar et al., 2019). Although it has been noted that interaction with educators is important, social presence of interacting with peers in the OLPs allow students to develop a mutual understanding and become closer to each other (Swan \& Shih, 2005). Additionally, unlike the interaction with educators, there have been two different results shown in past studies. One research shows that during collaborative learning, students tend to have less interaction with their team members (Heflin, Shewmaker \& Nguyen, 2017). In similar vein, Barbour and Bennett (2013) identified that building strong online relationships lead students to feel emotionally comfortable which leads them to be emotionally engaged in the learning environment. Gibbs and Poskitt (2010) also argued that this was a requirement for cognitive engagement. 
Figure 2: eLearn Homepage (Blackboard Inc.)
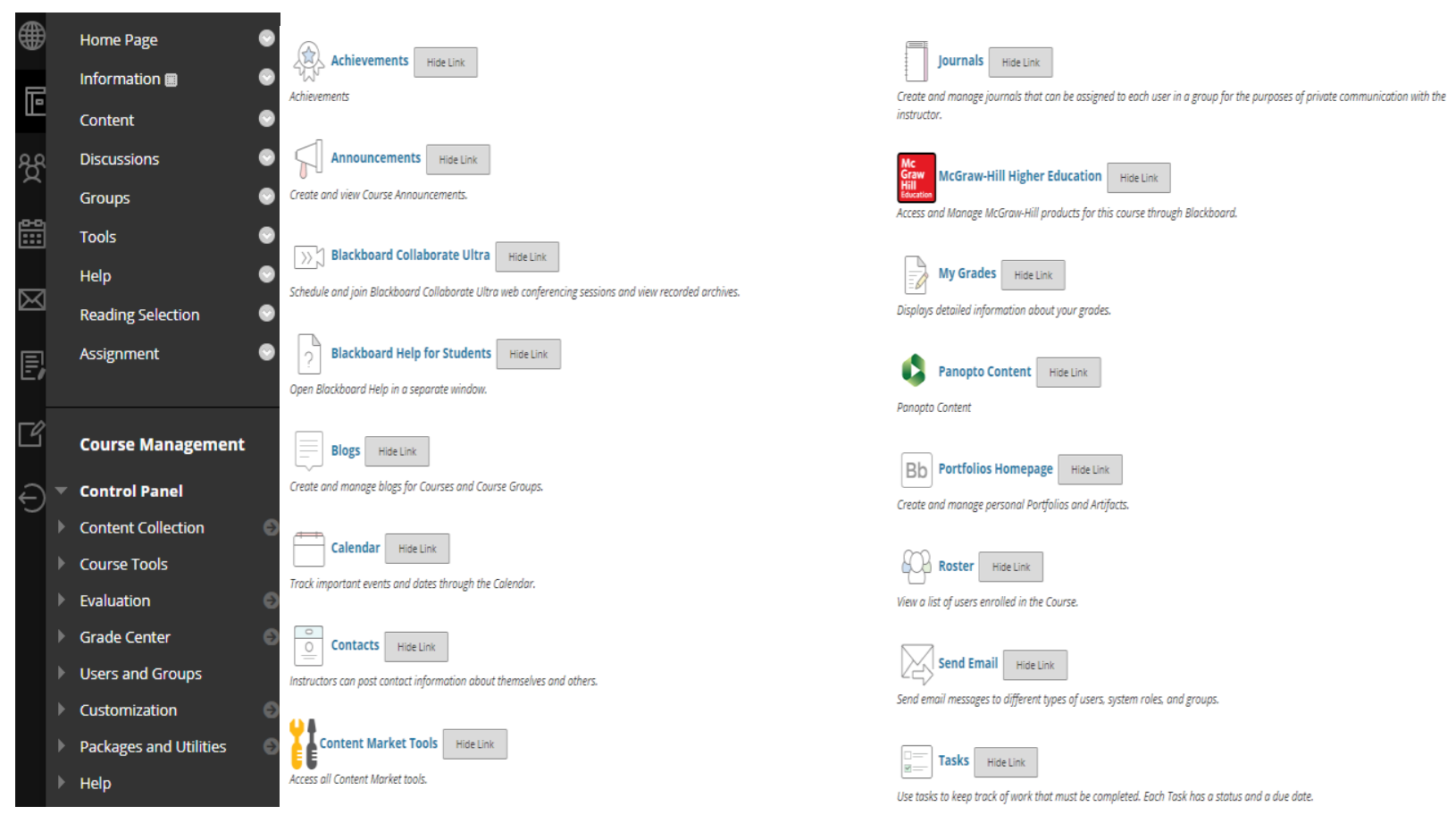

Lastly, OLPs can increase the level of interaction that students have with each other students and their teachers. The courses must be designed to include socially focused exchanges as an extension of core course content. For example, OLPs are used to increase students' participation in discussion forums, giving feedback on student input during classes, assessment feedback, and virtual tutorial classes (Walji, Deacon, Small, \& Czerniewicz, 2016). eLearn allows for these activities to be facilitated via features such as 'Blackboard Collaborate' for video conferencing, blogs, discussions, groups, organizations, and instructor-enabled class conversations (see Figure 2). Through these features, OLPs can increase the level of interaction that students have with each other students and their teachers. The interaction between students with peers and lecturers is vital in ensuring a quality online learning experience. OLPs that integrate suitable features and course designs that make room for social interaction is highly beneficial to learners. The myriad of features that eLearn provides is a prime indicator of how well the OLP can facilitate the interaction between students with peers and lecturers.

\section{Research Methodology}

This research employed a non-experimental research design in which a survey was developed and adapted from theoretical foundations of the identified variables, pertinent to the study. The survey was conducted to investigate the perceived usefulness of elearn, and to examine the features of eLearn, which contribute to students' satisfaction and facilitate interactions between students and students, and students and lecturers. The study was conducted in June 2020 and a total of 60 students from a private university in Klang Valley participated in this study, of which 30 students took this subject previously in January, 2020, via the face-to-face, and a portion of 
online deliveries semester, and 30 students took this subject in April, 2020, via 100\% online delivery semester.

First, the research topic was finalized by reading past studies based on interests. After understanding the arguments presented in the identified academic journals, the variables were finalized. The research instrument contained 4 sections, one for the survey demographic, and the rest encompassed items to probe the examined variables/ constructs. Each section comprised of 5 items. A Google form was used to administer the survey and the link was sent to prospective respondents via email and WhatsApp messages. The data and information were then collected anonymously and stored automatically in a spreadsheet, convenient for subsequent data analysis using Microsoft Excel.

Descriptive analyses were used to expound the findings. The frequency shows the number of students who perceived the online assessment is more convenient and reliable, the eLearn features that contributed to their satisfaction, and help facilitate the student-student and student-instructor interaction. The percentages juxtapose the number of students between the face-to-face classes and online classes from the linear scale towards the 15 statements which 5 of the statements belong to each objective. Lastly, the mean scores in the finding and discussion show the average number of students between the last semester face-to-face classes and online classes, and the average number of students between face-to-face classes and online classes from the table for further comparison.

\section{Findings and Discussion}

The total number of responses collected is 60 responses, where 28 responses are from students that took MAT1014 Calculus during the previous semester (January cohort) and 32 responses from students who are took the subject in April. To ensure equal comparison, only 28 students were randomly selected from each group.

Table 1: Perceived Usefulness of eLearn

\begin{tabular}{|c|c|c|c|c|c|c|c|c|c|c|}
\hline \multirow{2}{*}{ Items } & \multicolumn{5}{|c|}{ January Cohort } & \multicolumn{5}{|c|}{ April Cohort } \\
\hline & $S D$ & $D$ & $N$ & $A$ & $S A$ & $S D$ & $D$ & $N$ & $A$ & $S A$ \\
\hline $\begin{array}{l}\text { S1. User-friendly design and } \\
\text { navigation }\end{array}$ & 0 & 0 & 4 & 12 & 12 & 0 & 1 & 5 & 19 & 3 \\
\hline $\begin{array}{l}\text { S2. Live sessions via BB } \\
\text { collaborate }\end{array}$ & 0 & 2 & 3 & 14 & 9 & 0 & 5 & 5 & 15 & 3 \\
\hline $\begin{array}{l}\text { S3. Recorded live sessions } \\
\text { feature }\end{array}$ & 0 & 1 & 3 & 11 & 13 & 0 & 1 & 2 & 15 & 10 \\
\hline $\begin{array}{l}\text { S4. Notification of information } \\
\text { feature }\end{array}$ & 2 & 3 & 12 & 6 & 5 & 1 & 2 & 8 & 12 & 5 \\
\hline $\begin{array}{l}\text { S5. Due date and assignment } \\
\text { function }\end{array}$ & 0 & 2 & 6 & 14 & 6 & 0 & 3 & 8 & 11 & 6 \\
\hline Mean & 0.40 & 1.60 & 5.60 & 11.40 & 9.00 & 0.20 & 2.40 & 5.60 & 14.40 & 5.40 \\
\hline Std Dev & 0.80 & 1.02 & 3.38 & 2.94 & 3.16 & 0.40 & 1.50 & 2.24 & 2.80 & 2.58 \\
\hline
\end{tabular}


Table 1 illustrates the perceived usefulness of eLearn features and functions. For the January 2020 cohort, $85.7 \%(N=12, N=13)$ of the respondents agreed or strongly agreed with items S1 and S3 respectively. Items S2 and S5 both yielded the highest number of agreement (50\%), and $42.9 \%$ respondents were neutral for item S4. Item S4 is the only statement among all items S1 S5 that obtained responses for all options in the linear scale. For the April 2020 cohort, majority of the respondents agreed with the five survey items, denoting general consensus towards the usefulness of eLearn. Next, $89.3 \%$ of respondents agreed and strongly agreed with item S3. Among the items S1 to S5, 3.6\% of respondents strongly disagreed with item S4, while item S2 has the greatest number of respondents disagreeing with the statement, which is at $17.9 \%$. The mean scores range between 0.40 to 9.00 for the January cohort's respondents while for the April cohort, 0.20 to 5.40 were produced from the respective scale, suggesting a moderate to significant level of perceived usefulness among the respondents. From the results, it can be deduced that the January cohort found the available features and functions on elearn are more useful than the April cohort. This could be attributed to the fact that the January cohort might have been exposed to the eLearn general usage longer than the April cohort, influencing the overall readiness and satisfaction. A study resonates similar sentiment in which acquaintance and time provided to experiment with the technological tool can contribute to better understanding and usage (Kerzic, Tomazevic, Aristovnik, \& Umek, 2019). This finding is also supported by Wei and Chou, where they highlighted that online learning readiness and self-efficacy facilitate perceptions and satisfaction (2020). The in-built design and features on elearn enable for prescribed self-regulations, making students to be more prepared and motivated. It was noted in Kriz (2020) that these intended features facilitate better student engagement and organization.

Table 2: eLearn and Satisfaction

\begin{tabular}{|c|c|c|c|c|c|c|c|c|c|c|}
\hline \multirow{2}{*}{ Items } & \multicolumn{5}{|c|}{ January Cohort } & \multicolumn{5}{|c|}{ April Cohort } \\
\hline & $S D$ & $D$ & $N$ & $A$ & $S A$ & $S D$ & $D$ & $N$ & $A$ & $S A$ \\
\hline $\begin{array}{l}\text { S6. Announcement and note } \\
\text { features }\end{array}$ & 0 & 1 & 2 & 17 & 8 & 1 & 1 & 3 & 16 & 7 \\
\hline $\begin{array}{l}\text { S7. Forum and discussion } \\
\text { features }\end{array}$ & 1 & 6 & 14 & 6 & 1 & 3 & 5 & 12 & 7 & 1 \\
\hline $\begin{array}{l}\text { S8. Assessment feature (quiz, } \\
\text { test) }\end{array}$ & 0 & 1 & 6 & 13 & 8 & 1 & 0 & 4 & 15 & 8 \\
\hline $\begin{array}{l}\text { S9. Content/ course material } \\
\text { features }\end{array}$ & 0 & 0 & 2 & 14 & 12 & 1 & 0 & 2 & 14 & 11 \\
\hline $\begin{array}{l}\text { S10. Assessments submission } \\
\text { feature }\end{array}$ & 0 & 2 & 4 & 12 & 10 & 0 & 1 & 5 & 17 & 5 \\
\hline Mean & 0.20 & 2.00 & 5.60 & 12.40 & 7.80 & 1.20 & 1.40 & 5.20 & 13.80 & 6.40 \\
\hline Std Dev & 0.40 & 2.10 & 4.45 & 3.61 & 3.71 & 0.98 & 1.85 & 3.54 & 3.54 & 3.32 \\
\hline
\end{tabular}

Table 2 shows the various features on eLearn which are correlated with satisfaction. Most of the respondents in January cohort agreed or strongly agreed with almost all the statements/ items above except for item $\mathrm{S7}$, where $50 \%(\mathrm{~N}=14)$ of the respondents were neutral, $25 \%$ of respondents agreed, and $25 \%$ disagreed respectively. However, the number of respondents for the April cohort who chose 'strongly disagree' is greater, especially for item S7, where $28.6 \%$ 
were obtained. These results reflect how the design, features and functions on elearn are able to prompt satisfaction, not just from web-based application, but also specifically the available access from a mobile device (Menon, Zhang, \& Perrault, 2020), and assessment tools on eLearn such as quiz (Wong et. al. 2020). It is noteworthy to mention that the January cohort has a slightly higher agreement for items $\mathrm{S} 6(\mathrm{~N}=25)$ and $\mathrm{S9}(\mathrm{N}=26)$, compared with the April cohort $\mathrm{S} 6(\mathrm{~N}=23)$ and S9 $(\mathrm{N}=25)$. The April cohort produced higher responses for S7 and S8 which is expected due to the fully online semester, necessitating the leverages on features like forum, discussion and quiz, as opposed to the January cohort respondents who had the option of both online and face to face deliveries. This finding suggests that the development and design of the course resources, curriculum, instructional strategies affect learners' satisfaction and resonate results from previous studies (Gray \& Diloreto, 2016; Sahin, 2019; Wu, Wu, \& Li, 2019). It can be observed that the mean values for both January and April cohorts range from 12.4 to 13.8 for the agree scale, denoting significant degree of satisfaction.

Table 3: eLearn and Interaction

\begin{tabular}{|c|c|c|c|c|c|c|c|c|c|c|}
\hline \multirow{2}{*}{ Items } & \multicolumn{5}{|c|}{ January Cohort } & \multicolumn{5}{|c|}{ April Cohort } \\
\hline & $S D$ & $D$ & $N$ & $A$ & $S A$ & $S D$ & $D$ & $N$ & $A$ & $S A$ \\
\hline $\begin{array}{l}\text { S11. Interaction and "whiteboard" } \\
\text { features }\end{array}$ & 3 & 3 & 17 & 2 & 3 & 2 & 3 & 17 & 5 & 1 \\
\hline $\begin{array}{l}\text { S12. Interaction with lecturer and peers } \\
\text { via audio and chat features }\end{array}$ & 3 & 7 & 8 & 8 & 2 & 5 & 11 & 5 & 5 & 2 \\
\hline $\begin{array}{l}\text { S13. Motivation to answer questions } \\
\text { during live sessions via BB collaborate }\end{array}$ & 0 & 1 & 11 & 14 & 2 & 3 & 2 & 13 & 9 & 1 \\
\hline $\begin{array}{l}\text { S14. Preterence in using the chat teature } \\
\text { then the audio during live sessions via BB } \\
\text { collaborate }\end{array}$ & 1 & 0 & 2 & 11 & 14 & 1 & 0 & 4 & 10 & 13 \\
\hline $\begin{array}{l}\text { S15. The external link to access related } \\
\text { website is useful for peer interaction }\end{array}$ & 0 & 0 & 10 & 12 & 6 & 1 & 1 & 5 & 15 & 6 \\
\hline Mean & 1.40 & 2.20 & 9.60 & 9.40 & 5.40 & 2.40 & 3.40 & 8.80 & 8.80 & 4.60 \\
\hline Std Dev & 1.36 & 2.64 & 4.84 & 4.18 & 4.54 & 1.50 & 3.93 & 5.23 & 3.71 & 4.59 \\
\hline
\end{tabular}

Table 3 displays the essential eLearn features that act as a surrogate for interactions to exist online. The January cohort yields more neutral responses, especially for item S11. For items S12, S13, and S15, the total number of agreements is almost similar with the total number obtained for the neutral scale, and meanwhile, an agreement of $89.3 \%$ is attained for S14. These findings are rather interesting as it highlights the importance of online interaction and presence via eLearn. The April cohort, particularly for item S11 to S15, the number of agreements is higher than the number of disagreements, except for S12, where $57.1 \%$ of respondents disagreed with the statement, a higher percentage compared to the $25 \%$ of respondents who agreed. Item S11 has the greatest number of neutral responses. For the April cohort, items S11 and S15, the agreement yielded is more than the January cohort. This finding suggests that interaction and classroom participation are imperative for meaningful learning to occur (Berman, 2014; Lippmann, 2013). The built-in features on eLearn scaffold and stimulate interactions between peers, and also between students and instructor. As depicted in Table 3, the January cohort had employed these interactive features comparatively lesser than the April cohort. This is due to the 
reason that the January cohort had some portion of face to face interactions; thus, the frequency of using elearn to communicate is somewhat not needed. The mean scores span from 1.40 to 5.40 for the January cohort and 2.40 to 4.60 for the April cohort, representing substantial extent of interaction. Paulsen and McCormick reiterate similar notion in which instructional method and procedure contributes to the variant, specifically the compositional differences of student characteristics (2020).

\section{Conclusion}

With the aim to examine the effectiveness of elearn and its perceived usefulness and satisfaction, as well as how eLearn supports student-teacher and student-student interactions, this study generally discovered that the respondents from both cohorts are in consensus that eLearn is indeed valuable and beneficial, especially amidst the Covid-19 pandemic. This is reflected in both the responses gathered from January and April cohorts wherein several conclusions can be drawn. Firstly, the January cohort found the available features and functions on eLearn are more useful than the April cohort, and secondly, the April cohort produced more significant difference in the mean scores compared to the January cohort respondents who experienced both online and face to face instructions, and finally, January cohort had moderately lower responses in employing eLearn interactive features in contrast to the April cohort. With the findings, it is postulated that this research has a potential to be utilized as a point of reference, especially for educators who intend to employ eLearn as one of the OLPs in the teaching and learning setting. Thus, it is encouraged that universities identity innovative opportunities, provide guidelines or manual on how to specifically use these OLPs for both teachers and students, offer suitable trainings to improve overall understanding and engagement by leveraging on the integral features of the OLPs to scaffold different learning needs as well as to support virtual mobility. It is noteworthy to mention that elearn has a notable overall organization and layout which is imperative in assisting and supporting students at the initial stage while trying to accustom to the platform's navigations.

In a similar vein, eLearn has assessment features which makes it a one-stop, single system platform, facilitated through grading features with the use of rubrics, in-text comments, and summary comment areas. For future researches, it is recommended that researchers utilize various techniques when collecting data. For example, future researches can approach this topic by gathering qualitative data from interviews, open-ended questions when designing the survey for more detail of the respondents' responses, through observations or even conducting a quasiexperimental research design. Lastly, future researches can also include a larger sample size so that findings can be generalized and applied to a larger representation of population. 


\section{References}

Ahmad, C. N. C., Shaharim, S. A., \& Abdullah, M. F. N. L. (2017). Teacher-student interactions, learning commitment, learning environment and their relationship with student learning comfort. Journal of Turkish Science Education, 14(1), 57-72.

Akhtar, S., Hussain, M., Afzal, M., \& Gilani, S. (2019). Impact of Teacher-Student Interaction on Student Motivation and Achievement. European Academic Research, 7(2), 1201-1222.

Allen, I. E., \& Seaman, J. (2010). Learning on demand: Online education in the United States, 2009. Sloan Consortium. PO Box 1238, Newburyport, MA 01950.

Alqahtani, M., \& Mohammad, H. (2015). Mobile applications' impact on student performance and satisfaction. Turkish Online Journal of Educational Technology-TOJET, 14(4), 102-112.

Annansingh, F. (2019). Mind the gap: Cognitive active learning in virtual learning environment perception of instructors and students. Education and Information Technologies, 24(6), 3669-3688.

Aris, N., \& Orcos, L. (2019). Educational robotics in the stage of secondary education: Empirical study on motivation and STEM skills. Education Sciences, 9(2), 73.

Barbour, M., \& Bennett, C. (2013). The FarNet journey: Effective teaching strategies for engaging Mãori students on the Virtual Learning Network. Journal of Open, Flexible, and Distance Learning, 17(1), 12-23.

Berman, R. A. (2014). Engaging students requires a renewed focus on teaching. Chronicle of Higher Education, 61(3), 28-30.

Bernacki, M. L., Greene, J. A., \& Crompton, H. (2020). Mobile technology, learning, and achievement: Advances in understanding and measuring the role of mobile technology in education. Contemporary Educational Psychology, 60, 101827.

Blackmon, S. J., \& Major, C. (2012). Student experiences in online courses: A qualitative research synthesis. Quarterly Review of Distance Education, 13(2), 77-85.

Bulman, G., \& Fairlie, R. (2016). Technology and Education. Handbook of The Economics of Education, 5, 239-280.

Chung, E., Subramaniam, G., \& Dass, L. C. (2020). Online Learning Readiness among University Students in Malaysia amidst COVID-19. Asian Journal of University Education, 16(2), 4658.

Crawford, R. (2017). Rethinking teaching and learning pedagogy for education in the twenty-first century: blended learning in music education. Music Education Research, 19(2), 195-213.

Cochran, J. D., Baker, H. M., Benson, D., \& Rhea, W. (2016). Business student perceptions of online learning: Using focus groups for richer understanding of student perspectives. Organization Management Journal, 13(3), 149-166.

Davis, F. D., Bagozzi, R. P., \& Warshaw, P. R. (1989). User acceptance of computer technology: a comparison of two theoretical models. Management science, 35(8), 982-1003.

Faqih, K. M. S. (2016). Which is more important in e-learning adoption, perceived value or perceived usefulness? Examining the moderating influence of perceived compatibility. In eProceeding of the 4th Global Summit on Education, 372-398.

Gray, J. A., \& DiLoreto, M. (2016). The effects of student engagement, student satisfaction, and perceived learning in online learning environments. International Journal of Educational Leadership Preparation, 11(1). 
Gibbs, R., \& Poskitt, J. (2010). Student engagement in the middle years of schooling (Years 7-10): A literature review. A report to the New Zealand Ministry of Education. Retrieved from www.educationcounts.govt.nz/publications

Hallifax, S., Serna, A., Marty, J. C., \& Lavoue, E. (2019, September). Adaptive gamification in education: A literature review of current trends and developments. In European Conference on Technology Enhanced Learning (pp. 294-307). Springer, Cham.

Halili, S. H. (2019). Technological advancements in education 4.0. The Online Journal of Distance Education and E-Learning, 7(1), 63-69.

Heflin, H., Shewmaker, J., \& Nguyen, J. (2017). Impact of mobile technology on student attitudes, engagement, and learning. Computers \& Education, 107, 91-99.

Hodges, C., Moore, S., Lockee, B., Trust, T., \& Bond, A. (2020). The difference between emergency remote teaching and online learning. Educause Review, 27.

Holmes, K. A., \& Prieto-Rodriguez, E. (2018). Student and Staff Perceptions of a Learning Management System for Blended Learning in Teacher Education. Australian Journal of Teacher Education, 43(3), 21-34.

Horzum, M. B. (2017). Interaction, structure, social presence, and satisfaction in online learning. Eurasia Journal of Mathematics, Science and Technology Education, 11(3), 505-512.

Janus, E. S. (2020). The" Worst Idea Ever!"-Lessons from One Law School's Pioneering Embrace of Online Learning Methods. Syracuse L. Rev., 70, 13.

Kattoua, T., Al-Lozi, M., \& Alrowwad, A. A. (2016). A Review of Literature on E-Learning Systems in Higher Education. International Journal of Business Management \& Economic Research, 7(5), 754-762.

Kerzic, D., Tomazevic, N., Aristovnik, A., \& Umek, L. (2019). Exploring critical factors of the perceived usefulness of blended learning for higher education students. PloS one, 14(11), e0223767.

Kriz, T. D. (2020). Acadly: An Online Platform for Engaged Learning. Management Teaching Review, 2379298120947093.

Lippmann, S. (2013). Facilitating Class Sessions for Ego-Piercing Engagement. New Directions for Teaching and Learning, 138, $43-48$.

Mahmud, M. M. (2018). Technology and language-what works and what does not: A metaanalysis of blended learning research. Journal of Asia TEFL, 15(2), 365.

Mahmud, M. M., \& Ismail, O. (2020). Measuring Quality in Blended Learning: A Multimodal of the Sloan Consortium, Key Success Indicators and Transformative Driven Mechanism. In Proceedings of the 2020 11th International Conference on E-Education, E-Business, EManagement, and E-Learning (pp. 20-24).

Mahmud, M. M., Yaacob, Y., Ramachandiran, C. R., Ching, W. S., \& Ismail, O. (2019). Theories into Practices: Bloom's Taxonomy, Comprehensive Learning Theories (CLT) and EAssessments. ICEAP 2019, 2(2), 22-27.

Menon, S., Zhang, W., \& Perrault, S. T. (2020). Nudge for Deliberativeness: How Interface Features Influence Online Discourse. In Proceedings of the $2020 \mathrm{CHI}$ Conference on Human Factors in Computing Systems (pp. 1-13).

Mertala, P. (2019). Paradoxes of participation in the digitalization of education: A narrative account. Learning, Media and Technology, 45(2), 1-14. 
Moore, M. G. (1989). Three types of interaction. The American Journal of Distance Education, $3(2), 1-6$.

Mohammadi, H. (2015). Investigating users' perspectives on e-learning: An integration of TAM and IS success model. Computers in human behavior, 45, 359-374.

Ozhan, S. C., \& Kocadere, S. A. (2020). The effects of flow, emotional engagement, and motivation on success in a gamified online learning environment. Journal of Educational Computing Research, 57(8), 2006-2031.

Palomino, P. T., Toda, A. M., Oliveira, W., Cristea, A. I., \& Isotani, S. (2019). Narrative for gamification in education: why should you care?. In 2019 IEEE 19th International Conference on Advanced Learning Technologies (ICALT) (Vol. 2161, pp. 97-99). IEEE.

Paulsen, J., \& McCormick, A. C. (2020). Reassessing disparities in online learner student engagement in higher education. Educational Researcher, 49(1), 20-29.

Permatasari, G. A., Ellianawati, E., \& Hardyanto, W. (2019). Online Web-Based Learning and Assessment Tool in Vocational High School for Physics. Jurnal Penelitian \& Pengembangan Pendidikan Fisika, 5(1), 1-8.

Sahin, M. (2019). Classroom Response Systems as a Formative Assessment Tool: Investigation into Students' Perceived Usefulness and Behavioural Intention. International Journal of Assessment Tools in Education, 6(4), 693-705.

Selwyn, N. (2010). Looking beyond learning: Notes towards the critical study of educational technology. Journal of Computer Assisted Learning, 26(1), 65-73.

Stephens, M. L., \& Coryell, J. (2020). Faculty Perspectives on Context, Benefits, and Challenges in Fully Online Graduate Adult Education Programs. Adult Learning, 1045159520959468.

Sundgren, M. (2017). Blurring time and place in higher education with bring your own device applications: a literature review. Education and Information Technologies, 22(6), 30813119.

Swan, K., \& Shih, L. F. (2005). On the nature and development of social presence in online course discussions. Journal of Asynchronous learning networks, 9(3), 115-136.

Tastle, W. J., \& Wierman, M. J. (2007). Consensus and dissention: A measure of ordinal dispersion. International Journal of Approximate Reasoning, 45(3), 531-545.

Teras, M., Suoranta, J., Teras, H., \& Curcher, M. (2020). Post-Covid-19 education and education technology 'solutionism': A seller's market. Postdigital Science and Education, 2(3), 863-878.

Walji, S., Deacon, A., Small, J., \& Czerniewicz, L. (2016). Learning through engagement: MOOCs as an emergent form of provision. Distance Education, 37(2), 208-223.

Wei, H. C., \& Chou, C. (2020). Online learning performance and satisfaction: do perceptions and readiness matter? Distance Education, 41(1), 48-69.

Wong, S. F., Mahmud, M. M., \& Wong, S. S. (2020, April). Effectiveness of Formative E-assessment Procedure: Learning Calculus in Blended Learning Environment. In Proceedings of the 2020 8th International Conference on Communications and Broadband Networking (pp. 77-82).

$\mathrm{Wu}, \mathrm{Y}$. C. J., Wu, T., \& Li, Y. (2019). Impact of using classroom response systems on students' entrepreneurship learning experience. Computers in Human Behavior, 92, 634-645.

Zhai, X., \& Shi, L. (2020). Understanding How the Perceived Usefulness of Mobile Technology Impacts Physics Learning Achievement: A Pedagogical Perspective. Journal of Science Education and Technology, 29(6), 743-757. 